EXTENDED REPORT

\title{
Corneal graft rejection occurs despite Fas ligand expression and apoptosis of infiltrating cells
}

\author{
K A Williams, S D Standfield, J R Smith, D J Coster
}

Br J Ophthalmol 2005;89:632-638. doi: 10.1136/bjo.2003.040675

See end of article for authors' affiliations

.....................

Correspondence to:

Dr Keryn A Williams,

Department of

Ophthalmology, Flinders

Medical Centre, Bedford

Park, SA 5042, Australia; keryn.williams@flinders. edu.au

Accepted for publication 17 September 2004
Background/aims: Constitutive expression of Fas ligand (CD95L) protects the eye against cell mediated immune responses by inducing apoptosis in infiltrating Fas bearing $T$ cells. This study was designed to examine Fas ligand expression on acutely rejecting rat corneal grafts and to investigate the kinetics of induction of apoptosis in infiltrating leucocytes.

Methods: Orthotopic penetrating corneal transplantation was performed between genetically disparate inbred rats. Fas ligand expression and the phenotype of infiltrating leucocytes were examined by immunohistochemistry. Apoptotic nuclei were visualised in sections of normal rat cornea, rejecting allografts, and time matched isografts by terminal deoxynucleotidyl transferase mediated dUTP biotin nick end labelling (TUNEL) and quantified by video image analysis. Staining with Hoechst dye 33258 was used to confirm the presence of apoptotic nuclei.

Results: Fas ligand was expressed on corneal endothelial and epithelial cells during acute corneal graft rejection. At all time points examined, including as early as the fifth postoperative day, the cells infiltrating both corneal isografts and allografts were TUNEL positive. By the 15 th postoperative day, over $90 \%$ of all nuclei, many of which were $T$ cells, were apoptotic.

Conclusion: Expression of Fas ligand is not downregulated on the cornea during allograft rejection and infiltrating leucocytes in both isografts and allografts die rapidly in situ. Despite the death of the cells believed to be responsible for rejection, isografts survive indefinitely whereas allografts are irreparably damaged.
$\mathrm{T}$ he anterior segment of the eye is considered an immunologically privileged site in which allografts and xenografts exhibit prolonged survival. ${ }^{12}$ The mechanisms by which ocular privilege may be maintained include immunological ignorance, anterior chamber associated immune deviation (ACAID), and constitutive expression of Fas ligand (CD95L) on ocular tissue. ${ }^{1-8}$ Immunological ignorance represents a failure of the afferent arm of the immune response to be triggered by foreign antigen, or the failure of effector cells to gain access to target tissue. ${ }^{2}$ ACAID, which manifests as active suppression of the delayed type hypersensitivity response to antigen introduced into the anterior chamber, is mediated by immunosuppressive constituents of normal aqueous humour coupled with products of immunomodulatory effector cells generated through aberrant antigen processing pathways. ${ }^{3}$ Constitutive expression of Fas ligand on ocular tissue induces apoptotic cell death in infiltrating, Fas bearing $\mathrm{T}$ lymphocytes in a murine model of ocular herpes simplex virus infection. ${ }^{5}$ Furthermore, the incidence of corneal graft rejection increases markedly when graft donors are Fas ligand negative (gld) mice. ${ }^{6-8}$

Close evaluation of the outcome of transplantation of tissues at the anterior surface of the eye reveals that many grafts do fail from immunological rejection. ${ }^{9}{ }^{10}$ Kaplan-Meier survival of penetrating corneal allografts in large patient cohorts is approximately $60 \%$ at 10 years ${ }^{11}$ and the major cause of graft failure is irreversible rejection. ${ }^{11}{ }^{12}$ Similarly, immunological rejection appears to limit the success of limbal stem cell allotransplantation performed for bilateral blinding ocular surface disease both in humans ${ }^{13}$ and experimental animals $^{14}$ in the absence of adequate immunosuppression. Experimental corneal xenografts fail within a few days of graft as a result of antibody and complement mediated damage. ${ }^{15}{ }^{16}$ Thus, immune privilege is easily overwhelmed in the specific situation of transplantation into the cornea or at the ocular surface, despite multiple mechanisms that act to limit immune responsiveness.

We hypothesised that, should Fas ligand mediated apoptosis of infiltrating leucocytes be an important mechanism responsible for corneal privilege ${ }^{5}$ and corneal allograft survival in particular, ${ }^{6}$ then Fas ligand might be downregulated in acute corneal graft rejection and that a brief window might exist during which apoptosis did not occur. We tested this hypothesis in a model of orthotopic corneal transplantation in the rat.

\section{METHODS}

\section{Corneal transplantation}

Fischer 344 (F344; major histocompatibility complex (MHC) haplotype $\mathrm{RT}^{\mathrm{lvl}}$ ) and Wistar-Furth (WF; MHC haplotype $\mathrm{RT}^{\mathrm{u}}$ ) rats were bred within the institution. F344 rats were recipients of corneal grafts from either F344 (isograft) or WF (allograft) donors. Unilateral right $3 \mathrm{~mm}$ diameter penetrating orthotopic corneal transplantation was performed under general anaesthesia between adult sex matched pairs as previously described. ${ }^{17}$ Rejection appeared as increasing corneal opacification in a previously thin, clear corneal graft and was always associated with graft neovascularisation. The day of rejection was defined as the day that iris margins were no longer clearly visible through the grafted cornea. Median corneal graft survival in the WF to F344 strain combination is 16-17 days ${ }^{18}$ : indefinite graft survival was defined as survival of a clear graft for at least 60 days.

Abbreviations: ACAID, anterior chamber associated immune deviation; dUTP, deoxy-uridine triphosphate; FCS, fetal calf serum; MHC, major histocompatibility complex; NSS, normal swine serum; PBS, phosphate buffered saline; RT, room temperature; TUNEL, terminal deoxynucleotidyl transferase mediated dUTP biotin nick end labelling 


\section{Immunohistochemistry}

Polyclonal rabbit anti-rat CD95L (Fas ligand) antibodies (FAS-L (N-20) \#sc-834, detecting amino acids mapping to the amino terminus of rat CD95L; FAS-L (C-178) \#sc-6237, detecting amino acids mapping to the carboxy terminus of rat CD95L) (Santa Cruz Biotechnologies Inc, Santa Cruz, CA, USA) were used at $5 \mu \mathrm{g} / \mathrm{ml}$. Heat inactivated normal rabbit serum diluted to $5 \mu \mathrm{g} / \mathrm{ml}$ immunoglobulin was used as the normal control. Grafted eyes were fixed $2-4$ hours at $4{ }^{\circ} \mathrm{C}$ in paraformaldehyde-lysine-periodate solution, ${ }^{19}$ soaked for 18 hours at $4^{\circ} \mathrm{C}$ in $7 \%$ weight/volume $(\mathrm{w} / \mathrm{v})$ sucrose in phosphate buffered saline (PBS; $150 \mathrm{mM} \mathrm{NaCl,} 6 \mathrm{mM}$ $\mathrm{Na}_{2} \mathrm{HPO}_{4}, 4 \mathrm{mM} \mathrm{KH} \mathrm{KO}_{4}, \mathrm{pH} 7.2$ ) and subsequently for 6 hours in 15\% w/v sucrose in PBS before snap freezing in liquid nitrogen. Sections cut at $8 \mu \mathrm{m}$ on the cryostat were transferred to chrome-alum subbed slides and blocked in $10 \%$ volume/volume $(\mathrm{v} / \mathrm{v})$ heat inactivated normal swine serum (NSS; Trace Biosystems, Sydney, Australia) at room temperature (RT). They were incubated with primary antibody for 18 hours at RT and washed three times with PBS containing $0.2 \% \mathrm{w} / \mathrm{v}$ gelatin (Ajax, Auburn, Australia). Following incubation with biotinylated affinity isolated sheep anti-rabbit immunoglobulins (Silenus, Melbourne, Australia) diluted $1 / 100$ in PBS containing $1 \% \mathrm{v} / \mathrm{v}$ heat inactivated normal rat serum, $1 \%$ heat inactivated NSS, and $1 \%$ heat inactivated fetal calf serum (FCS; Trace Biosystems, Sydney, Australia) for 30 minutes at RT, sections were washed three times with PBS-gelatin and incubated with horseradish peroxidase conjugated streptavidin (Dako Corporation, Carpinteria, CA, USA) diluted $1 / 1000$ in PBS for 30 minutes at RT, and washed three times in PBS-gelatin. The reaction product was developed for 5 minutes with a solution of $0.1 \mathrm{M}$ TRIS- $\mathrm{HCl}$ buffer, $\mathrm{pH} 7.6$, containing $0.3 \% \mathrm{w} / \mathrm{v}$ sodium azide,

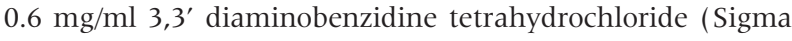
Chemical Company, St Louis, MO, USA), $10 \mathrm{mM}$ imidazole, and $0.07 \% \mathrm{v} / \mathrm{v}$ hydrogen peroxide (Ajax, Auburn, Australia). Sections were counterstained with haematoxylin, dehydrated through graded alcohols to xylene and mounted in Depex (BDH, Poole, UK).

Immunohistochemistry using monoclonal antibodies on paraformaldehyde-lysine-periodate fixed sections of grafted eyes was performed as described elsewhere. ${ }^{16}$ Monoclonal antibodies were undiluted culture supernatants from stationary phase murine hybridoma cultures obtained from the ECACC (Porton Down, Salisbury, Wiltshire, UK) unless otherwise specified. Isotype matched negative controls X63 (IgG1) and SAL5 (IgG2a) were the gift of Professor H Zola, Adelaide, Australia; OX18, an anti-MHC class I antibody, was the positive control. Specific antibodies included OXI, antiCD45; OX35, OX38, W3/25, all anti-CD4; OX8, anti-CD8; NDS61, anti-IL-2R; OX42, anti-iC3b receptor (macrophage and granulocyte); EDl, anti-macrophage, monocyte, and some dendritic cells. Sections were counterstained with haematoxylin to allow nuclear morphology to be assessed. Staining was assessed at the light microscope using a semiquantitative scoring system as follows: $-=$ no positively stained infiltrating cells; $+=$ few positively stained infiltrating cells; $+=$ moderate number of positively stained infiltrating cells; $+++=$ many positively stained infiltrating cells. Sections from two to three isografts and two to three allografts were examined at days 5, 7, 12, 14, 21, and 28 post-graft.

Terminal deoxynucleotidyl transferase mediated dUTP biotin nick end labelling (TUNEL)

TUNEL was performed according to a modification of a published method. ${ }^{20}$ Grafted rat eyes or lymph nodes from normal rats were removed post mortem, fixed in $4 \%$ buffered formalin for a minimum of 24 hours and paraffin embedded.
Sections of $5 \mu \mathrm{m}$ were adhered to slides precoated with a $1 / 50$ dilution of Histogrip (Zymed, San Francisco, CA, USA) in acetone, deparaffinised, hydrated through graded alcohols to distilled water, and permeabilised with $4 \mu \mathrm{g} / \mathrm{ml}$ proteinase $\mathrm{K}$ (Merck, Darmstadt, Germany) for 10 minutes at RT. Nick end labelling was accomplished by incubating sections with 0.11 units/ml terminal deoxynucleotidyl transferase in $\mathrm{pH} 6.6$ buffer containing $5 \mathrm{mM}$ cobalt chloride, $200 \mathrm{mM}$ potassium cacodylate, $25 \mathrm{mM}$ TRIS- $\mathrm{HCl}, 250 \mu \mathrm{g} / \mathrm{ml}$ bovine serum albumin, $0.375 \mathrm{nM}$ biotinylated deoxy-uridine triphosphate (dUTP), and $75 \mu \mathrm{M}$ deoxy-adenosine triphosphate (all from Boehringer-Mannheim, Mannheim, Germany) for 60 minutes at $37^{\circ} \mathrm{C}$. The reaction was terminated by washing in $0.6 \mathrm{M}$ sodium chloride $/ 0.06 \mathrm{M}$ sodium citrate buffer for 15 minutes at RT, in PBS for 1 minute at RT, and in PBS containing $2 \% \mathrm{v} / \mathrm{v}$ FCS and $0.2 \% \mathrm{v} / \mathrm{v}$ Triton-X100 (Sigma, St Louis, MO, USA) for 30 minutes at RT. Non-specific binding sites were blocked with $10 \%$ heat inactivated NSS for 10 minutes at RT, and the sections were washed for 10 minutes with PBS-gelatin before endogenous peroxidase was blocked with $0.09 \% \mathrm{v} / \mathrm{v} \mathrm{H}_{2} \mathrm{O}_{2}$ in methanol for 20 minutes at RT. Sections were washed in PBS-gelatin for 10 minutes at RT, and then incubated with a 1/300 dilution of horseradish peroxidase conjugated streptavidin (Dako Corporation, Carpinteria, CA, USA) in PBS for 1 hour at RT. Sections were washed three times with PBS-gelatin, and were then developed, counterstained, and mounted as described above. Negative control sections were stained identically, but with omission of biotinylated dUTP from the nick end labelling mixture.

\section{Video image analysis of TUNEL sections}

A whole sagittal section through the centre of each grafted cornea was examined. Sections were scanned at $200 \times$ magnification using a video image analysis system (VideoPro 32; Leading Edge Pty Ltd, Adelaide, Australia). Images were captured using a Panasonic CCD video camera and digitised with a PV 10016 bit colour video digitiser card in an Intel 80486 DX processor based personal computer. The digitised image was displayed on a SVGA monitor in a $640 \times 480$ pixel variable window with 21 bit resolution. Transmitted light intensity and stability of light output were standardised as described elsewhere. ${ }^{21}$ Video image analysis measurements were made of the total area stained blue (by haematoxylin) and brown (by the TUNEL chromogen product). The total number of haematoxylin stained cell nuclei (representing nuclei of corneal cells and infiltrating cells) in each field was determined using feature counting.

\section{Staining with Hoechst dye $\mathbf{3 3 2 5 8}$}

Hoechst dye 33258 (bis-benzimide; Sigma, St Louis, MO, USA) was used to visualise apoptotic nuclei..$^{22}$ Rat thymus was teased apart with forceps in HEPES RPMI 1640 medium supplemented with 100 units $/ \mathrm{ml}$ penicillin, $100 \mu \mathrm{g} / \mathrm{ml}$ streptomycin, and $2 \mathrm{mM}$ glutamine (all from ICN-Flow, Sydney, Australia) and $10 \% \mathrm{v} / \mathrm{v}$ heat inactivated FCS. The cell suspension was filtered through a sterile gauze, washed twice in medium and adjusted to $4 \times 10^{7}$ viable cells/ml. Equal volumes of cell suspension were incubated for 20 hours at $37^{\circ} \mathrm{C}$ with or without $1 \mathrm{mM}$ dexamethasone (David Bull Laboratories, Melbourne, Australia). The cells were washed in medium, fixed for 10 minutes at RT in $2.6 \% \mathrm{v} / \mathrm{v}$ formaldehyde, $2 \% \mathrm{w} / \mathrm{v}$ glucose, and $0.005 \mathrm{M} \mathrm{NaN}_{3}$ in PBS, washed twice in distilled water, and adjusted to $5 \times 10^{6}$ cells/ $\mathrm{ml}$. A volume of $10 \mu \mathrm{l}$ of cell suspension was smeared on a glass slide, allowed to air dry and stained with $10 \mu \mathrm{g} / \mathrm{ml}$ Hoechst dye 33258 in distilled water for 30 minutes at RT. The slides were washed twice in distilled water, air dried and mounted in 50\% v/v glycerol in PBS. To prepare whole 

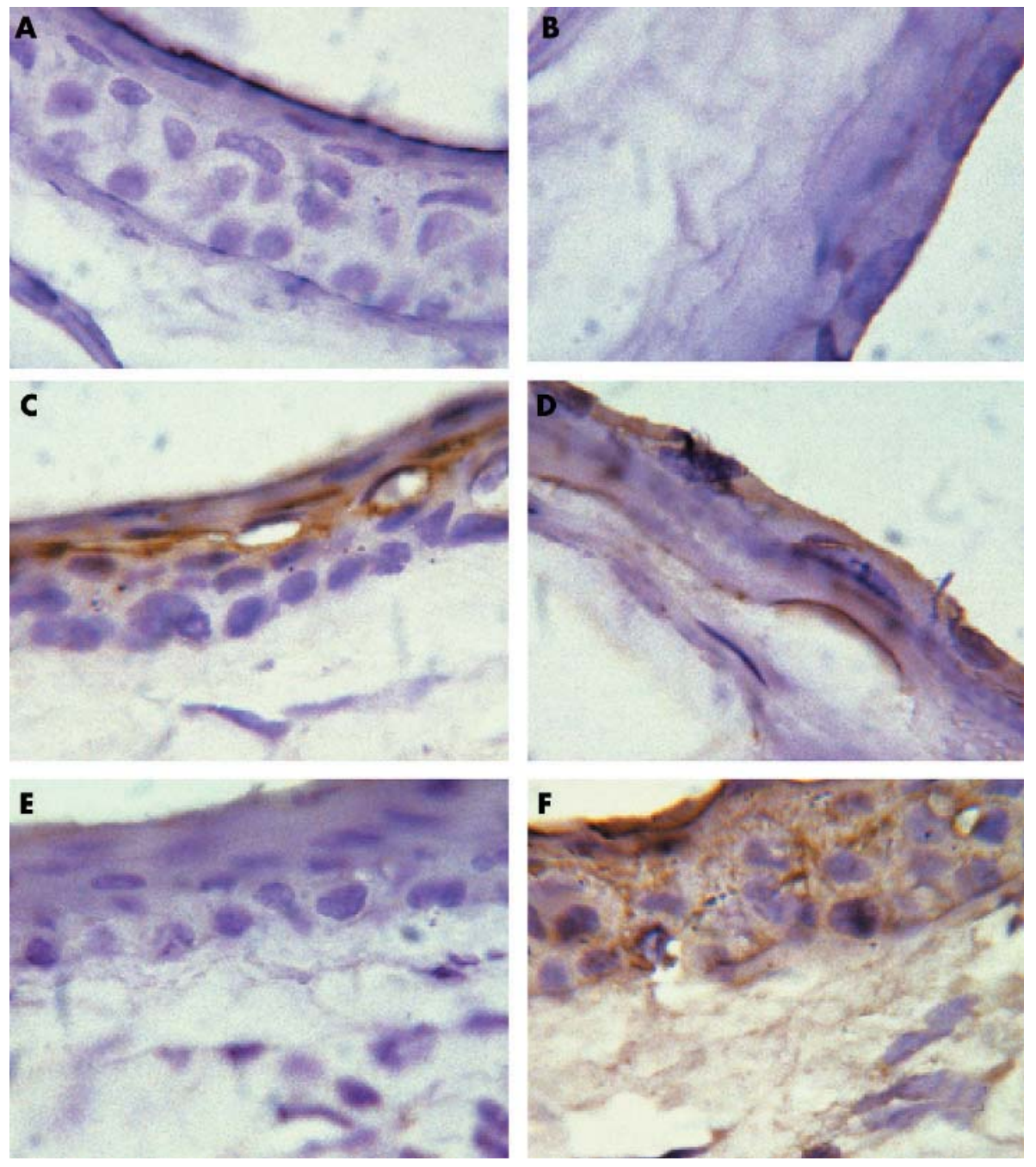

Figure 1 Immunoperoxidase staining (A) Normal rat corneal epithelium, negative control: normal rabbit serum, $5 \mu \mathrm{g} / \mathrm{ml}$ total immunoglobulin; (B) normal rat corneal endothelium and posterior stroma, negative control: normal rabbit serum, $5 \mu \mathrm{g} / \mathrm{ml}$ total immunoglobulin; (C) normal rat corneal epithelium, anti-Fas ligand (FAS-L (N20)), $5 \mu \mathrm{g} / \mathrm{ml}$ specific antibody; (D) normal rat corneal endothelium and posterior stroma, anti-Fas ligand (FAS-L (N20)), $5 \mu \mathrm{g} / \mathrm{ml}$ specific antibody; (E) corneal allograft, day 15 post-graft, negative control: normal rabbit serum, $5 \mu \mathrm{g} / \mathrm{ml}$ total immunoglobulin; (F) corneal allograft, day 15 post-graft, anti-Fas ligand (FAS-L (N20)), $5 \mu \mathrm{g} / \mathrm{ml}$ specific antibody. A light haematoxylin counterstain was applied to all sections; the dark brown staining represents diaminobenzidine reaction product. mounts, rat corneas were excised at the limbus, immersed in the dye solution for 30 minutes at RT, washed twice by immersion in distilled water, and mounted in 50\%v/v glycerol in PBS. Smears and whole mounts were examined under the fluorescence microscope at an excitation wavelength of 360$370 \mathrm{~nm}$.

\section{RESULTS}

Fas ligand as detected by FAS-L (N20) was present on normal rat corneal epithelium and endothelium (fig 1). Similar expression was observed on rat corneal allografts harvested at 15 days post graft during acute rejection (fig 1). No downregulation of Fas ligand was apparent: expression may have actually been upregulated. The same pattern of expression was seen with FAS-L (C-178) (data not shown).

Apoptotic nuclei in sections of rat tissue were visualised by TUNEL. Some positive staining of cells in the corneal epithelium of normal rat corneas was observed and occasional keratocytes and corneal endothelial cells were also positive (fig 2A). Many cells infiltrating rat corneal isografts (fig $2 \mathrm{~B}$ ) and the majority of cells infiltrating acutely rejecting allografts (fig 2D) were TUNEL positive. Apoptotic mononuclear cells were observed attached to the corneal endothelium. Some keratocytes also appeared TUNEL positive. No staining was observed in the controls in which biotinylated dUTP was omitted (fig 2C). Rat lymph node showed very few strongly TUNEL positive cells confined to germinal centres (fig 2E, F), thereby confirming that the strong positive staining observed in the corneal grafts was not non-specific staining of all leucocytes.

In a kinetic study, grafts were stained for TUNEL at postoperative day 0 (immediately post-graft), day 5 (when infiltrating cells were first observed in the grafted tissue), day 10 (early allograft rejection), day 15 (acute allograft rejection), day 21 (late allograft rejection), and (in the case of isografts only) more than 60 days (long surviving grafts). The percentages of TUNEL positive nuclei in the stroma of corneal allografts, time matched isografts, and normal control rat corneas were quantified by video image analysis (table 1). The striking increase in the percentage positivity observed with increasing time after transplantation in rejecting allografts primarily reflected the greater number of infiltrating mononuclear cells contributing to the total cell count at these times.

To confirm the TUNEL results using another method of detecting apoptotic nuclei, corneas were stained with Hoechst dye 33258. As a positive control, apoptosis was induced in a suspension of rat thymocytes by incubation with dexamethasone. After staining with Hoechst 33258, the preparation showed many small bright fragmented nuclei with condensed chromatin, typical of apoptotic figures (fig 3A). Comparison of normal rat corneas (fig 3B) and rejecting corneal allografts (fig 3C) similarly stained with Hoechst 33258 and examined as whole mounts showed numerous brightly staining nuclei with condensed chromatin in the stroma of the latter only. 

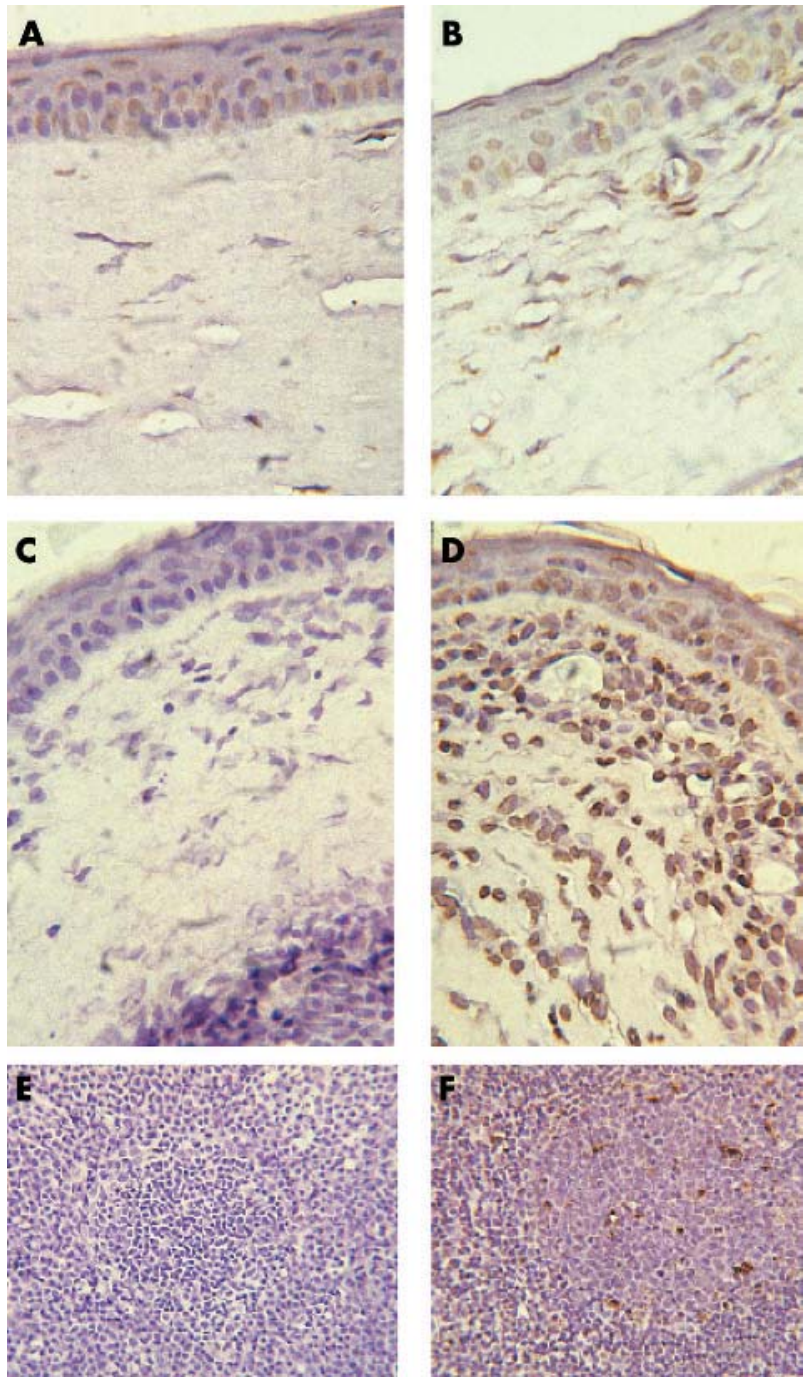

Figure 2 TUNEL staining. (A) Normal rat cornea; (B) corneal isograft, day 15 post-graft; (C) corneal allograft, day 15 post-graft: negative control, dUTP omitted from nick end labelling mixture; (D) corneal allograft, day 15 post-graft; (E) normal rat lymph node: negative control, dUTP omitted from nick end labelling mixture; (F) normal rat lymph node. A light haematoxylin counterstain was applied to all sections; the dark brown staining represents the TUNEL reaction product.
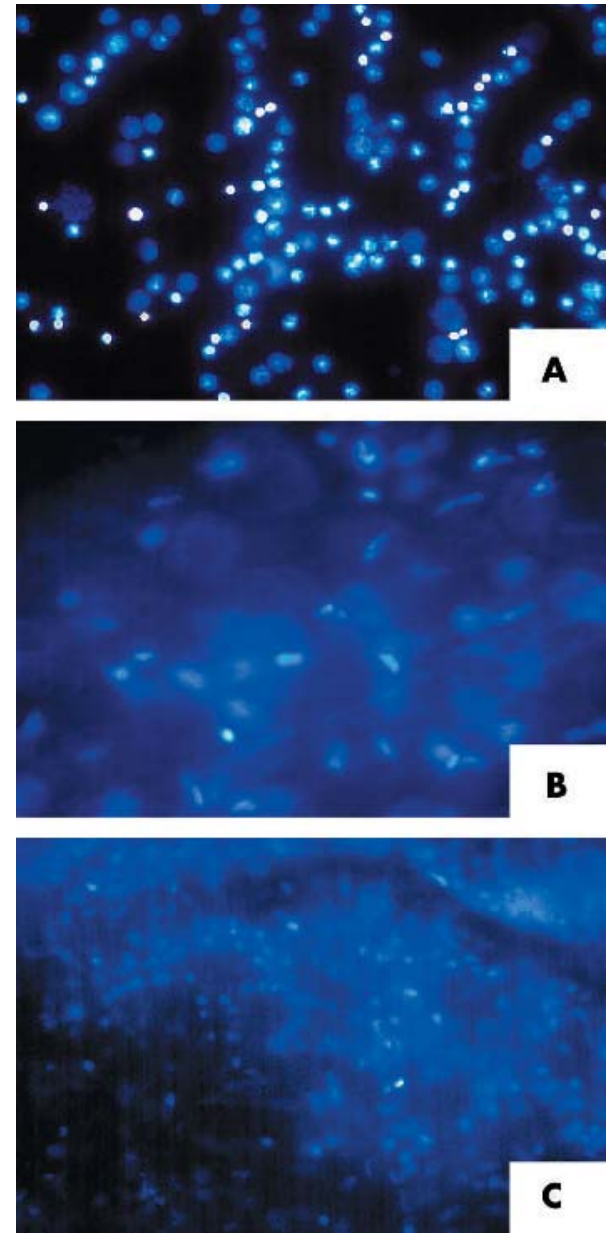

Figure 3 Hoechst dye 33258 staining. (A) Rat thymocytes incubated 20 hours at $37^{\circ} \mathrm{C}$ with $1 \mathrm{mM}$ dexamethasone; (B) whole mount of normal rat cornea; $(C)$ whole mount of rejecting corneal allograft.

To characterise more closely the phenotype of the TUNEL positive cells infiltrating isografts and allografts in this model, immunohistochemistry for rat leucocytic markers was performed on isografts and allografts at varying time points after graft (table 2 ). No staining was observed with the negative control antibodies in any section and the positive

\begin{tabular}{|c|c|c|c|}
\hline \multirow[b]{2}{*}{ Specimen } & \multirow[b]{2}{*}{ No of eyes* } & \multicolumn{2}{|c|}{$\begin{array}{l}\text { Mean (SD) \% TUNEL + } \\
\text { nuclei in corneal stroma }\end{array}$} \\
\hline & & Without dUTP ${ }^{\dagger}$ & With dUTP $\neq$ \\
\hline Normal corneas & 5 & $1.7(2.3)$ & $29.3(15.3)$ \\
\hline Isograft day 0 & 3 & $1.5(3.1)$ & $35.3(17.6)$ \\
\hline Isograft day 5 & 3 & $1.7(2.7)$ & $50.1(19.2)$ \\
\hline Isograft day 10 & 3 & $0.3(0.8)$ & 33.9 (14.8) \\
\hline Isograft day 14 & 3 & $1.5(1.4)$ & $47.9(28.8)$ \\
\hline Isograft day 21 & 3 & $0.4(0.9)$ & $65.0(22.8)$ \\
\hline Isograft day $>60$ & 4 & $0.9(0.9)$ & 42.5 (16.3) \\
\hline Allograft day 0 & 3 & $2.1(4.0)$ & $29.2(19.9)$ \\
\hline Allograft day 5 & 3 & $2.4(3.0)$ & 57.8 (10.4) \\
\hline Allograft day 10 & 3 & $0.8(0.9)$ & 75.3 (12.4) \\
\hline Allograft day 15 & 3 & $8.4(4.7)$ & $93.6(6.3)$ \\
\hline Allograft day 21 & 3 & $0.8(1.4)$ & $78.3(18.0)$ \\
\hline
\end{tabular}


control antibody showed appropriate staining in all sections. In isografts, a few CD45 positive cells had moved into the graft by the fifth postoperative day, clustered primarily in the periphery around the graft sutures. These cells were predominantly granulocytes, macrophages, and/or dendritic cells as judged by positivity with OX42 and EDl. Cells bearing $\mathrm{T}$ cell markers were extremely rare in isografts at all times examined. No leucocytes were observed in the anterior chamber of isografts at any time. In allografts, an early infiltrate of granulocytes, macrophages, and/or dendritic cells at the graft-host junction was observed. At day 5 post-graft, there were more cells bearing the iC $3 \mathrm{~b}$ receptor in allografts than in isografts. T cells were already present in allografts at day 5 post-graft and increased in number in the central cornea during rejection. The influx of CD4 positive cells preceded the influx of CD8 positive cells by at least a week. CD4 positive cells were also found in the anterior chamber after 1 week, whereas CD8 positive cells were not noted until day 21 . Small numbers of neutrophils were identified by their nuclear morphology in some allografts.

Dual immunoperoxidase and TUNEL staining on the same sections was not performed because of the different processing required for the two protocols. However, all sections were inspected at the light microscope to assess concordance of staining. As pointed out above, some corneal epithelial cells, and occasional keratocytes and corneal endothelial cells, were TUNEL positive and therefore presumably apoptotic. These cells were readily identifiable from their location and morphology and were apparent in normal corneas, isografts, and allografts. The cells infiltrating isografts were predominantly myeloid lineage cells with very sparse numbers of $\mathrm{T}$ cells, and were mostly TUNEL positive irrespective of phenotype. These same cells were also TUNEL positive in allografts but the majority of infiltrating cells, especially in the central areas of the grafts, were TUNEL positive T cells.

\section{DISCUSSION}

In normal rat cornea, Fas ligand was detected by immunohistochemistry on epithelial and endothelial cells. Both mouse $^{56}$ and human ${ }^{6}$ cornea have previously been shown to express Fas ligand constitutively, and thus our finding was not unexpected. However, the rejection rate of normal murine corneal grafts has been reported to be of the order of $45-47 \%$ across at common strain combinations. ${ }^{67}$ In contrast, approximately $85-100 \%$ of corneal grafts from WF donors to F344 recipients are rejected at a median of 1617 days postoperatively ${ }^{18}$ without the need for deliberate prevascularisation of the recipient cornea. In the light of these differences, we hypothesised that Fas ligand might be significantly downregulated during acute corneal graft rejection in the rat, thereby allowing infiltrating $\mathrm{T}$ cells to survive and mediate rejection. However, in this model both epithelial and endothelial cells remained strongly positive for Fas ligand product as detected by two different antibodies against the amino and carboxy termini, respectively, of the molecule.

The expected result of expression of Fas ligand would be induction of apoptosis in Fas bearing infiltrating leucocytes (including CD4+ $\mathrm{T}$ cells, CD8+ $\mathrm{T}$ cells, neutrophils, and macrophages) as has already been shown in transplanted corneas in the mouse, ${ }^{6}$ and this was precisely what we observed. The TUNEL method was used to visualise apoptotic cells and was coupled with video image analysis for the quantification of the number of apoptotic nuclei. Normal rat corneas exhibited some positive TUNEL staining in epithelium, as has been reported previously. ${ }^{23}$ Occasional keratocytes and corneal endothelial cells were also TUNEL positive, but there was no leucocytic infiltrate in normal corneas. In contrast, isografts showed a slight cellular infiltrate of cells bearing myeloid lineage markers that were mostly localised to the area of the graft-host junction, whereas allografts showed a more marked, central infiltrate of leucocytes that were predominantly $\mathrm{T}$ cells. The identity and kinetics of infiltration of leucocytes in rat corneal isografts and allografts was essentially as has been described previously in our own and other laboratories. ${ }^{18}{ }^{24-26}$ Virtually all infiltrating leucocytes in both isografts and allografts were apoptotic as judged by positive TUNEL staining.

We examined the time of appearance of apoptotic cells in rejecting orthotopic rat corneal grafts and in time matched isografts. Metalloproteinases have been reported to release human Fas ligand from the cell surface ${ }^{27}$; the cleaved soluble Fas ligand is an inefficient trigger of apoptosis and instead may competitively inhibit membrane bound Fas ligand induced cell death. ${ }^{28}{ }^{29}$ Furthermore, Fas ligand induced killing of $\mathrm{T}$ cells requires $\mathrm{T}$ cell receptor stimulation. ${ }^{30}{ }^{31} \mathrm{We}$ therefore suspected that there might be a brief time period during which infiltrating cells in allografts were TUNEL negative, perhaps through release of Fas ligand from the surface of corneal cells, and that the small number of $\mathrm{T}$ cells infiltrating isografts might not undergo apoptosis because their $\mathrm{T}$ cell receptors would not have been ligated by foreign antigen. However, cells infiltrating both isografts and allografts appeared to undergo apoptosis as soon as they interacted with corneal tissue, although the effect was more pronounced in the allografts. An infiltrate was first observed at the light microscope at about day 5 postoperatively and at

Table 2 Identity of cells infiltrating rat corneal isografts and allografts

\begin{tabular}{|c|c|c|c|c|c|c|c|}
\hline \multirow[b]{2}{*}{ Antibody specificity } & \multirow[b]{2}{*}{ Specimen* } & \multicolumn{6}{|c|}{ Cellular infiltrate at day post-graftt } \\
\hline & & 5 & 7 & 12 & 14 & 21 & 28 \\
\hline \multirow[t]{2}{*}{ CD45 } & Isograft & + & + & + & ++ & ++ & $+1-$ \\
\hline & Allograft & ++ & ++ & ++ & +H+ & +r+ & ++ \\
\hline \multirow[t]{2}{*}{ CD4 } & Isograft & - & + & + & - & $+/-$ & $+1-$ \\
\hline & Allograft & $+/-$ & + & ++ & ++ & ++ & $+1-$ \\
\hline \multirow[t]{2}{*}{ CD8 } & Isograft & - & + & - & - & NT & - \\
\hline & Allograft & $+/-$ & $+/-$ & $+/-$ & $+/-$ & ++ & + \\
\hline \multirow[t]{2}{*}{ IL2R } & Isograft & - & - & $+1-$ & - & - & - \\
\hline & Allograft & - & - & $+1-$ & + & ++ & + \\
\hline \multirow[t]{2}{*}{ iC3bR } & Isograft & + & + & + & + & NT & - \\
\hline & Allograft & +++ & + & + & ++ & ++ & ++ \\
\hline \multirow[t]{2}{*}{ ED1 } & Isograft & +++ & + & + & + & + & - \\
\hline & Allograft & +++ & + & + & ++ & ++ & ++ \\
\hline
\end{tabular}


this time point, the infiltrating cells were already TUNEL positive. We did not observe a window in which infiltrating cells were TUNEL negative: the increasing percentage of TUNEL positive nuclei observed with increasing time postgraft reflected a steady increase in the number of infiltrating leucocytes present in the corneal tissue. Modulators of apoptosis, such as Bcl-2 and various growth factors, are expressed by human corneal cells, in tissue sections and/or in culture. ${ }^{32-34}$ Expression of such modulators may be altered during corneal graft rejection, but not to the extent that apoptosis is blocked.

TUNEL has been used previously to study apoptosis within the cornea, ${ }^{35}{ }^{36}$ and we consider our staining technique to be reliable. Firstly, the negative controls (in which biotinylated dUTP was omitted) consistently showed minimal positive staining (table 1). Secondly, normal cornea showed the expected pattern of TUNEL positivity (primarily in basal epithelium), whereas normal rat lymph node was negative. Thirdly, apoptotic nuclei within allografts (but not normal corneas) were directly visualised by staining of corneal whole mounts with the nuclear dye Hoechst 33258, an independent test for condensed chromatin and apoptotic-like nuclear figures. Attempts to confirm the TUNEL staining ${ }^{37}$ by extracting DNA from rejecting corneal grafts and running the extracts on agarose gels ${ }^{20}$ produced inconsistent DNA laddering, because the small size of the grafts limited the amount of DNA available for extraction (data not shown). Finally, induction of apoptosis in infiltrating Fas positive cells was entirely consistent with the observation that the cornea continued to express Fas ligand during the rejection process. Our data do not allow us to draw a causal link between Fas ligand expression and induction of apoptosis in cells infiltrating corneal grafts in the rat, but elegant experiments ${ }^{67}$ in which the incidence of corneal allograft rejection was strongly enhanced when mutant Fas ligand negative (gld) were used as donors provide such evidence for the mouse and, by extension, for other species.

How, then, do corneal grafts undergo rejection? Corneal graft rejection appears histologically to be an inflammatory process with characteristics typical of a delayed type hypersensitivity response: the infiltrate is mixed, but is composed predominantly of $\mathrm{T}$ cells. ${ }^{39-41}$ In the non-inflammatory programmed cell death that occurs as part of normal development, apoptotic nuclei are quickly cleared by phagocytosis. ${ }^{42}$ TUNEL positive cells may accumulate in rejecting corneal grafts because there are insufficient phagocytic cells present in the grafts to clear the substantial number of dead and dying $\mathrm{T}$ cells. Although apoptosis is a rapid process, it may be that infiltrating $\mathrm{T}$ cells can kill their targets more quickly, so that "murder" precedes "suicide.." ${ }^{43}$ Alternatively, Sonoda and colleagues have shown that CDId positive NKT cells can induce allospecific regulatory $\mathrm{T}$ cells that may promote corneal graft survival. ${ }^{44}$ Should these cells be induced to undergo apoptosis early in the alloresponse, then perhaps a crucial control mechanism may be abrogated.

It has been suggested that the "immunological privilege" enjoyed by the eye and the testis, two organs that express Fas ligand constitutively, might be adapted to prevent the rejection of other grafts by using Fas ligand as a natural immunosuppressant. ${ }^{45}$ Fas ligand transfected myoblasts syngeneic with murine recipients have been reported to prevent rejection of co-transplanted islet allografts. ${ }^{47}$ However, Allison and his colleagues ${ }^{48}$ have reported that expression of Fas ligand on fetal pancreatic islets taken from mice transgenic for $\mathrm{CD} 95 \mathrm{~L}$ failed to protect those grafts from rejection and, furthermore, the transgenic donors developed a granulocytic infiltration of islet tissue. Our data suggest acute corneal graft rejection occurs in the presence of expressed Fas ligand even in otherwise normal recipient eyes. In eyes that have been inflamed or where the cornea is vascularised, ${ }^{10}$ there is overwhelming evidence in a variety of species, including humans, to support the contention that rejection is the expected outcome for corneal grafts. Immune privilege in the eye is plainly relative and can be overcome, but the mechanism by which rejection occurs, given that so many of the cells presumed to be involved are dead, remains obscure.

\section{ACKNOWLEDGEMENTS}

The authors thank Mr R Yates for expert assistance with animal husbandry and Dr SL Wesselingh for advice on the TUNEL method.

\section{Authors' affiliations}

K A Williams, S D Standfield, D J Coster, Department of

Ophthalmology, Flinders University of South Australia, Adelaide, Australia

J R Smith, Casey Eye Institute, Oregon Health and Science University, Portland, OR, USA

This work was supported by grants from National Health and Medical Research Council of Australia and the Ophthalmic Research Institute of Australia. Dr Smith is supported by a Career Development Award from Research to Prevent Blindness. There are no commercial or proprietary interests related to this manuscript.

\section{REFERENCES}

1 Medawar PB. Immunity to homologous grafted skin. III. The fate of skin homografts transplanted to the brain, to subcutaneous tissue, and to the anterior chamber of the eye. Br J Exp Pathol 1948;29:58-69.

2 Barker CF, Billingham RE. Immunologically privileged sites. Adv Immunol 1977;25:1-54.

3 Streilein JW, Niederkorn JY. Induction of anterior chamber-associated immune deviation requires an intact, functional spleen. J Exp Med $1981 ; 153: 1058-67$

4 Streilein JW. Ocular immune privilege: therapeutic opportunities from an experiment of nature. Nat Rev Immunol 2003;3:879-89.

5 Griffith TS, Brunner T, Fletcher SM, et al. Fas ligand-induced apoptosis as a mechanism of immune privilege. Science 1995;270:1189-92.

6 Stuart P, Griffith TS, Usui N, et al. CD95 ligand (FasL)-induced apoptosis is necessary for corneal allograft survival. J Clin Invest 1997;99:396-402.

7 Yamagami S, Kawashima H, Tsuru T, et al. Role of Fas-Fas-ligand interactions in the immunorejection of allogeneic mouse corneal transplants. Transplantation 1997:64:1107-11.

8 Green DR, Ferguson TA. The role of Fas ligand in immune privilege. Nat Rev Mol Cell Biol 2001;2:917-24.

9 Williams KA, Coster DJ. Rethinking immunological privilege: implications for corneal and limbal stem cell transplantation. Mol Med Today 1997:3:495-501.

10 Coster DJ, Williams KA. Management of high-risk corneal grafts. Eye 2003;17:996-1002

11 Williams KA, Muehlberg SM, Lewis RF, et al. How successful is corneal transplantation? A report from the Australian Corneal Graft Register. Eye 1995;9:219-27.

12 Vail A, Gore SM, Bradley BA, et al. Influence of donor and histocompatibility factors on corneal graft outcome. Transplantation 1994;58:1210-16.

13 Henderson TR, Coster DJ, Williams KA. The long term outcome of limbal allografts: the search for surviving cells. Br J Ophthalmol 2001;85:604-9.

14 Swift GJ, Aggarwal RK, Davis GJ, et al. Survival of rabbit limbal stem cell allografts. Transplantation 1996;62:568-74.

15 Ross JR, Howell DN, Sanfilippo FP. Characteristics of corneal xenograft rejection in a discordant species combination. Invest Ophthalmol Vis Sci 1993;34:2469-76

16 Larkin DF, Takano T, Standfield SD, et al. Experimental orthotopic corneal xenotransplantation in the rat, mechanisms of graft rejection. Transplantation 1995:60:491-7.

17 Williams KA, Coster DJ. Penetrating corneal transplantation in the inbred rat: a new model. Invest Ophthalmol Vis Sci 1985;26:23-30.

18 Takano T, Williams KA. Mechanism of corneal endothelial destruction in rejecting rat corneal allografts and xenografts: a role for CD4+ cells. Transplant Proc, 1995; b, 260-1.

19 McLean IW, Nakane PK. Periodate-lysine-paraformaldehyde fixative: a new fixative for immunoelectron microscopy. J Histochem Cytochem 1974;22:1077-83.

20 Smith JR, Hart PH, Standfield SD, et al. Apoptosis of infiltrating cells is prominent in acute anterior uveitis in the Fischer 344 rat. Br J Ophthalmol 2000;84:205-11.

21 Tilley WD, Lim-Tio SS, Horsfall DJ, et al. Detection of discrete androgen receptor epitopes in prostate cancer by immunostaining: measurement by video image analysis. Cancer Res 1994:54:4096-102.

22 Yanagihara K, Tsumuraya M. Transforming growth factor $\beta 1$ induces apoptotic cell death in cultured human gastric carcinoma cells. Cancer Res 1992;52:4042-5. 
23 Ren H, Wilson G. Apoptosis in the corneal epithelium. Invest Ophthalmol Vis Sci 1996;37:1017-25.

24 Holland EJ, Olsen TW, Chan CC, et al. Kinetics of corneal transplant rejection in the rat penetrating keratoplasty model. Cornea 1994;3:317-23.

25 Larkin DF, Calder VL, Lightman SL. Identification and characterization of cells infiltrating the graft and aqueous humour in rat corneal allograft rejection. Clin Exp Immunol 1997;107:381-91.

26 Claerhout I, Kestelyn P, Debacker V, et al. Role of natural killer cells in the rejection process of corneal allografts in rats. Transplantation 2004:77:676-82

27 Kayagaki N, Kawasaki A, Ebata T, et al. Metalloproteinase-mediated release of human Fas ligand. J Exp Med 1995;182:1777-83.

28 Tanaka $M$, Itai $T$, Adachi $M$, et al. Downregulation of Fas ligand by shedding Nat Med 1998:4:31-6.

29 Brunner T, Wasem C, Torgler R, et al. Fas (CD95/Apo-1) ligand regulation in $\mathrm{T}$ cell homeostasis, cell-mediated cytotoxicity and immune pathology. Sem Immunol 2003; 15:167-76.

30 Wong B, Arron J, Choi Y. T cell receptor signals enhance susceptibility to Fasmediated apoptosis. J Exp Med 1997;186:1939-44.

31 Siegal RM, Chan FK, Chun HJ, et al. The multifaceted role of Fas signaling in immune cell homeostasis and autoimmunity. Nat Immunol 2000;1:469-74.

32 Wilson SE, Li Q, Weng J, et al. The Fas-Fas ligand system and other modulators of apoptosis in the cornea. Invest Ophthalmol Vis $\mathrm{Sci}$ 1996;37:1582-92.

33 Yamamoto K, Ladage PM, Ren DH, et al. Bcl-2 expression in the human cornea. Exp Eye Res $2001 ; 73: 247-55$.

34 Yanai R, Yamada N, Kugimiya N, et al. Mitogenic and antiapoptotic effects of various growth factors on human corneal fibroblasts. Invest Ophthalmol Vis Sci 2002;43:2122-6.

35 Gain P, Thuret G, Chiquet C, et al. Value of two mortality assessment techniques for organ cultured corneal endothelium: trypan blue versus TUNEL technique. Br J Ophthalmol 2002;86:306-10.
36 Albon J, Tullo AB, Aktar S, et al. Apoptosis in the endothelium of human corneas for transplantation. Invest Ophthalmol Vis Sci 2000;41:2887-93.

37 Ansari B, Coates PJ, Greenstein BD, et al. In situ end-labelling detects DNA strand breaks in apoptosis and other physiological and pathological states. J Pathol 1993;170:1-8.

38 Gold R, Schmied M, Rothe G, et al. Detection of DNA fragmentation in apoptosis: application of in situ nick translation to cell culture systems and tissue sections. J Histochem Cytochem 1993;41:1023-30.

39 Williams KA, Coster DJ. Clinical and experimental aspects of corneal transplantation. Transplantation Reviews 1993:7:44-64.

40 Williams KA, Standfield SD, Wing SJ, et al. Patterns of corneal graft rejection in the rabbit and reversal of rejection with monoclonal antibodies. Transplantation 1992;54:38-43.

41 Ayliffe W, Alam Y, Bell EB, et al. Prolongation of rat corneal graft survival by treatment with anti-CD4 monoclonal antibody. $\mathrm{Br} J$ Ophthalmol 1992;76:602-6.

42 Morris RG, Hargreaves AD, Duvall E, et al. Hormone-induced cell death. 2 Surface changes in thymocytes undergoing apoptosis. Am J Pathol 1984:115:426-36.

43 Strasser A. Death of a cell. Nature 1995;373:385-6.

44 Sonoda KH, Tabiguchi M, Stein-Streilein J. Long-term survival of corneal allografts is dependent on intact CDId-reacitive NKT cells. J Immunol 2002; 168:2028-34.

45 Bellgrau D, Gold D, Selawry H, et al. A role for CD95 ligand in preventing graft rejection. Nature 1995;377:630-2.

46 Vaux DL. Ways around rejection. Nature 1995;377:576-7.

47 Lau HT, Yu M, Fontana A, et al. Prevention of islet allograft rejection with engineered myoblasts expressing FasL in mice. Science 1996;273:109-12.

48 Allison J, Georgiou HM, Strasser A, et al. Transgenic expression of CD95 ligand on islet $\beta$ cells induces a granulocytic infiltration but does not confer immune privilege upon islet allografts. Proc Natl Acad Sci USA 1997:94:3943-7. 